\title{
Production, Quantitative Analysis of Fatty Acids, Engine Performance and Emission Characteristics of Biodiesel Fuel Derived from Virgin Coconut Oil
}

\author{
Alex Y \\ M.Tech Scholar, (Machine Design) \\ Mechanical Department \\ Saintgits College of Engineering, Kottayam, Kerala
}

\author{
Roji George Roy \\ M.Tech Scholar, (Machine Design) \\ Mechanical Department \\ Saintgits College of Engineering, Kottayam, Kerala
}

\begin{abstract}
Biodiesel has become more attractive recently, because of its environmental benefits and the fact that it is made from renewable resources. Over the past few decades, most of the countries depending on diesel engines for transportation. Some of its valuable advantages like highest thermal efficiency made it very popular. At the same time, the cost of diesel fuel is increasing, due to the depletion of fossil fuels. In this current scenario, we need an alternative fuel instead of diesel fuel. Many of the researchers have successfully placed several works on generating energy from different types of alternative sources including solar and some kind of conversion processes including renewable agricultural products into liquid fuel. One of the biggest challenges for developing countries in relation to energy consumption is to develop and implement technologies that help to improve efficiency of automobile engines, also to reduce the emissions of harmful gases and particulate matters. In order to avoid environmental impacts, emissions are reduced or eliminated by introducing renewable energy resources.
\end{abstract}

The present research chronicles the production and testing of renewable biodiesel fuel derived from virgin coconut oil on a diesel engine, to analyses the engine performance and emission characteristics. In the first phase of work, production of biodiesel fuel from virgin coconut oil using transeterification process with two types of catalysts (homogenous and heterogeneous). The preliminary results shows that, with the addition of homogenous catalyst called Potassium Hydroxide (KOH) with methanol shows much higher activity than that of heterogeneous catalysts, and it shows more similar properties with diesel fuel.

The results obtained from the chemical test and physicochemical properties of transesterified biodiesel fuel clearly proves the above-mentioned statement. The chemical tests such as GCMS and FT-IR clearly shows that the biodiesel fuel has sufficient amount of volatile components and functional groups. Then, physicochemical properties include, Fire point, Flashpoint, density, and viscosity were analyzed. Finally, Engine performance and Emission characteristics were analysed to confirm, whether this biodiesel fuel is suitable for diesel engines, without any engine modifications. It was found to be, the transesterified virgin coconut oil biodiesel has similar properties to that of the diesel fuel. From the physiochemical properties and engine performance clearly shows that, coconut oil biodiesel is suitable for diesel engine on blending, at a blending percentage level of $20 \%$ with conventional diesel fuel. Since the obtained transesterified biofuel can be used as an alternative fuel for diesel engines. The several journal reports and find outs from experimental investigation clearly depicts that the efficiency of the transesterified biofuel mainly depends upon the amount of catalyst adding and type of catalysts present in the biofuel, whether it is homogenous or heterogeneous catalyst is suitable with methanol. Finally, from the analysis made from biodiesel fuel. Coconut Oil Biodiesel fuel has less emission characteristics than that of the diesel fuels.

Keywords:- Biodiesel fuel; virgin coconut oil biodiesel; homogenous catalyst; heterogeneous catalyst; transesterification process.

\section{INTRODUCTION}

Fuel energy demand and crisis are considered as the primary concern of the world. The world's non-renewable energy resources is depleting day-by-day, it led to an improved interest in search for alternative fuels. Biodiesel is considered to be an alternative fuel to diesel engines, because it can be produced from vegetable oils. It consists of long-chain fatty acid esters. It has low emissions, nontoxic and it is biodegradable. It is a promising clean alternative fuel and also bio degradable. Biodiesel itself could be used or blended with fuel (Diesel) in any proportions. Alphabetic letter B indicates biodiesel proportions. Biodiesel in purest form in B100, or if $20 \%$ of biodiesel is blended with fuel it is represented as B20. In car engines, it is studied in recent years biodiesel can be mixed with diesel fuel or directly substituted as alternative fuel to diesel fuel without any engine modifications [1]. The first use of biodiesel as alternative for diesel engine is introduced by Rudolf diesel during First World War. The use of oils from coconut, soybean, sunflower, rapeseed and palm oil (feedstocks in the form of edible and non-edible types) amongst others have been attempted. Some of the reasons because of the endurance issue through long term use in engines leads the limited usage in vegetable oils as fuel. To overcome this difficult situation, various modifications are made into the engines for better output with biodiesel as fuel [2]. 
To obtain crude oil or fat, Vegetable oils and animal fats are extracted. These usually contain sterols, free fatty acid, water, odorants, phospholipids and impurities [3]. Also, fats and refined oils contains water and free fatty acids. Higher levels of unsaturated fatty acids are owned by some glycerides and at room temperature they are liquid. High viscosities, fats it is not possible to use bio diesel directly because it contains fatty acids which are saturated. At room temperature they are solid so that in the original form the fuel cannot be used directly in diesel engine. With the use of oils and fats as diesel fuels the problem arises are there will be carbon deposits, lubrication oil contamination and engine durability [4]. From these results obtained and discussed, it is very evident that because of the close fuel properties of virgin coconut oil is referred as good feedstock for biodiesel production as a blend to diesel fuel and can be used in the diesel engines of automobiles and industries with minimum or without modifications.

Biodiesel of coconut oil was discovered to have certain properties better than other biodiesels. The Coconut oil biodiesel has high flash point and also saponification value is one highest for the manufacture of soaps, detergents and shampoo products. The density and viscosity of the coconut oil and its biodiesel was low. The iodine value is high, that is high content of unsaturated fat acids. The low value of acid tells fuel can't be corrosive because high acid [5]. Finally, it is concluded that coconut oil is one of the best vegetable oils for the production of biodiesel. From the results obtained it is understood that the feedstock of coconut oil is good for production of biodiesel and without modification biodiesel can be used in conventional diesel engine due closeness properties of properties of fuel [6]. Among of these biodiesel derived from coconut oil, for better efficiency, the researchers introduce a technology. Microemulsions, thermal cracking (industrially termed as pyrolysis), transezterification, blending and direct use are primary methods to make biodiesel. Most of the researchers and industrialists using transezterification process for the processing of biodiesel from animal fats and vegetable oils. Type of catalyst added, molar ratio of glycerides to alcohol content, reaction temperature, time period for reaction and free fatty acid contents, which includes water content of fats and oil are considered as some of the important factors that affect the transezterification process. Thus the technology introduced called transezterification process. This was considered to be the most suitable modification process. The methodological properties of the esters are nearly similar to that of conventional diesel fuel.

Through transezterification process, the conversion of the triglycerides into alkyl esters of the fatty acids present in the vegetable oil [7, 8]. In transezterification process with the suitable catalyst and alcohol the triglycerides are converted into mixtures of glycerol and esters. If the oil with content of free fatty acid is greater than $5 \%$, it cannot be used directly in transezterification. The yield of biodiesel would get lowered if base catalyst reacted with free fatty acid. So, a pre-treatment stage which is called esterification is required to remove the content of free fatty acid [9].The Biodiesel is produced by transesterication process, the parent or base oil or fat with an alcohol, usually suggested methanol or propanol, in presence of a catalyst. These are usually comes under a strong base or acidic medium. Now a days, researchers from the field of fuel technology recommend instead of acidic medium, base is better for biodiesel production, because of its characteristics. Therefore, the catalysts, such as sodium, potassium hydroxides or if possible and gradually more commonly, alkoxides are using for the processes [10].

This paper focused on the biodiesel production from virgin coconut oil. Results obtained shows that feedstock added has the properties close to biodiesel standards and diesel fuel standards. Therefore, instead of using diesel fuel oil to diesel engine, it can be substituted as a blended fuel, for long term use. Based on the available results and studies, the feedstock used in the process has the advantage that, it is a non-polluting source of fuel; hence, it helps in reducing the greenhouse gases emissions and other emissions that are toxic and cacogenic. This experimental work is mainly pointed to produce biodiesel fuel from ethyl esters of coconut oil and comparing the physiochemical properties and chemical properties of the biodiesel with ASTM standards [11].

\section{MATERIALS AND METHOD}

\section{A. Coconut Oil Biodiesel Production:}

The feedstock used for the biodiesel production was virgin coconut, purchased from the local markets in kerala state, from Athikkalam mills in Alappuzha (nedumudy). The coconut oil was extracted by piercing the coconut with a mechanical cutters or manually by using knifes and taking the flesh of the coconut from the shell for further processing. Then the nuts were cut into small pieces. With the help of conventional oil extracting machines, it is blended with a blender. The coconut milk was collected in a vessel, which filtered by filtering process, with the help of human power. Then the filtered milk was left for 24-48 hours in a closed room. As it get sets the coconut milk and oil got separated, and at the top of the container a layer of curd appeared, the curd was scooped out thereby leaving the crude coconut oil and hence the coconut oil is extracted.

\section{B. Transesterification process:}

Preparation of Potassium methoxide was made by dissolving $0.5 \mathrm{~g}$ of $\mathrm{KOH}$ in $100 \mathrm{~cm} 3$ of methanol. A $20 \mathrm{ml}$ of coconut oil was mixed with $100 \mathrm{~cm} 3$ of potassium methoxide. It is then stirred at $600 \mathrm{rpm}$ at a temperature of $50{ }^{\circ} \mathrm{C}$ for 2 hours in a volumetric flask. The mixture is then poured into a separating funnel and allowed to stay for a night for the reaction to be get over and the mixture is separated into two layers of biodiesel and denser glycerol remains at the bottom. The glycerol was drained off. Then the biodiesel fuel was washed with purified distilled water and is stirred gradually to remove impurities. Then it is then allowed to settle for 2-3 hours in room temperature, over a flask. Using separating funnel the two layers were formed. Thus the pure biodiesel and hydrated methanol was separated. 
The oil was heated to a particular temperature, in order to speed up the reaction process. About 120-140 F was the ideal temperature. The reaction can take days at room temperatures and is inhibited above $140 \mathrm{~F}$. The easiest way to bring up the oil up to temperature required was to heat with electric elements.

The need of mixing methanol and the catalyst $(\mathrm{KOH})$ is to react the two substances to produce methoxide. $\mathrm{KOH}$ and Methanol are dangerous chemicals. Hence care was taken not to touch skin. $\mathrm{KOH}$ will not instantly dissolve into methanol and $\mathrm{KOH}$ was added slowly. As the particles of $\mathrm{KOH}$ cannot be seen the methoxide was ready to be used. The mixing duration was from 20-30minute. The glycerol was allowed to settle at the bottom of the separating funnel after the transezterification reaction, because glycerol is heavier than biodiesel. The mixture was left a minimum of 9-10 hours to make sure all of the glycerol has settled out. The glycerol volume was found to be almost $20 \%$ of the original oil volume [12]. Some impurities like un-reacted methanol; potassium methoxide and possibly potassium alkylate (soap) are the products of the transezterification reaction. Before it can be used in diesel engine it requires purification. Water is a suitable solvent for dissolving because all the impurities are polar group. Using a measuring cylinder, $20 \mathrm{~cm} 3$ of water was measured and was poured on the product sample. The mixture was gently stirred to avoid the formation of foam. The mixture of water and biodiesel was left for 16 hours to settle that is water-impurities phase and biodiesel phase. Using a separating funnel the two phase mixture was then separated. The biodiesel layer then heated to for 1 hour about $100{ }^{\circ} \mathrm{C}$ so that remaining water molecules gets evaporated.

\section{Blending Properties:}

In our experiment we are blending coconut biodiesel to diesel in various percentage ranging from $10 \%, 20 \%$ and $30 \%$. From the referred journal we can come to following conclusion [13]. The properties of blends of coconut oil are comparable with those of conventional diesel. In the case of engine performance, blends of coconut oil biodiesel produces similar brake power efficiency as that of the diesel fuel at lower proportion level, even at higher proportion $(30 \%)$ of coconut oil blends is efficient and shows higher brake power and net heat release rate than that of the diesel fuel. From the journal papers and experimental results Cleary depicts that adding of $30 \%$ biodiesel to conventional diesel is good for its performance [14].

\section{RESULTS AND DISCUSSION}

\section{A. Chemical Analysis:}

Chemical Analysis of a biodiesel is to identify the components present in the oil. To confirm whether it is suitable for an alternative to diesel fuels. For that, here we used three different types of testing, to confirm the volatility. They are: Fourier Transform Infrared Spectrozcopy (FT-IR), Gas Chromatography-Mass Spectrometry (GCMS), and Thermo-Gravimetric Analysis
(TGA). Based on the available results only, to confirm that the prepared biodiesel is suitable for diesel engines.

\section{$>$ Fourier Transform Infrared Spectrozcopy (FTIR)}

The experimental method was developed for determining the infrared spectrum of absorption or emission of a solid, liquid or gas. The spectrometer used in this technique, which simultaneously collects high-spectralresolution data over a wide spectral range. The concentration of coconut oil biodiesel, and its blends with petrodiesel were analysed using FTIR Spectrozcopy. The results shows that, the results obtained in this work shows that, the prepared virgin coconut oil biodiesel fuel has good ability for determining the concentration of biodiesel, which similar to petrodiesel. One of the strengths of IR Spectrozcopy is derived from the fact that specific functional groups, such as $\mathrm{CH}_{3}, \mathrm{CH}_{2}, \mathrm{OH}, \mathrm{COOH}, \mathrm{NH}_{2}$, etc., were present in the feedstock as much needed to volatile. Each absorb is defined wavelength regions shows their presence to some degree, and the relative proportions of each ones. The technique is mainly aims to show the functional groups activated on the given sample, thus the results by FTIR method shows the two different functional groups of fatty acid ethyl esters in the samples.

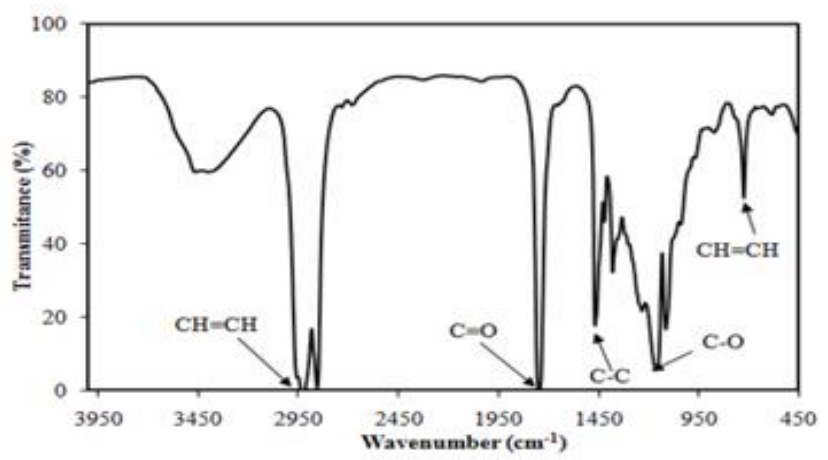

Fig 1:- FTIR Image of Coconut oil Biodiesel

From the available results, the FTIR for coconut oil biodiesel (Fig. 1) indicates, two main functional groups of fatty acid ethyl esters $(\mathrm{C}=\mathrm{O}$ and $\mathrm{C}-\mathrm{O}$ compounds have 1734 $\mathrm{cm}^{-1}$ and, $1155 \mathrm{~cm}^{-1}$ respectively). In addition to this, the crude glycerol was lightly brownish in colour and is required to develop this reaction at desired conditions. On the other hand, the biodiesel was a transparent liquid, which is similar to that of the petro-diesel, suggesting an acceptable quality and it is termed to an alternative fuel as based on its compound structure. The bandwidth of 3500$3450 \mathrm{~cm}^{-1}$ is attributed to the presence of small quantity of remnant water content, which was obtained during washing of crude biodiesel fuel.

\section{> Gas Chromatography-Mass Spectrometry (GCMS)}

The main objective of this experimental investigation was to identify and study the fatty acid composition of virgin coconut oil by this method. Helium was used as the carrier gas. Fatty Acid Methyl Esters peaks present in the biodiesel fuel sample were identified by comparing their retention time and equivalent chain length with respect to standards. 
From the model results, there are different types of compounds were present, from that more preferably saturated, mono saturated, poly saturated and unsaturated compounds were presented. The saturated compounds such as capric acid (C10:0), lauric acid (C12:0), myristic acid (C14:0), palmitic acid (C16:0), stearic acid (C18:0), and arachidic acid (C20:0) were found to be at different levels. Also Mono saturated compound named oleic acid (C18:1) and finally Polyunsaturated compound linoleic acid (C18:2) and linolenic acid (C18:3) were found to be at specified composition levels, but the percentages vary [16, 17]. These available results shows there was a clear presence of volatile components in the feedstock, so this is suitable for fuel as an alternative fuel to diesel engine.

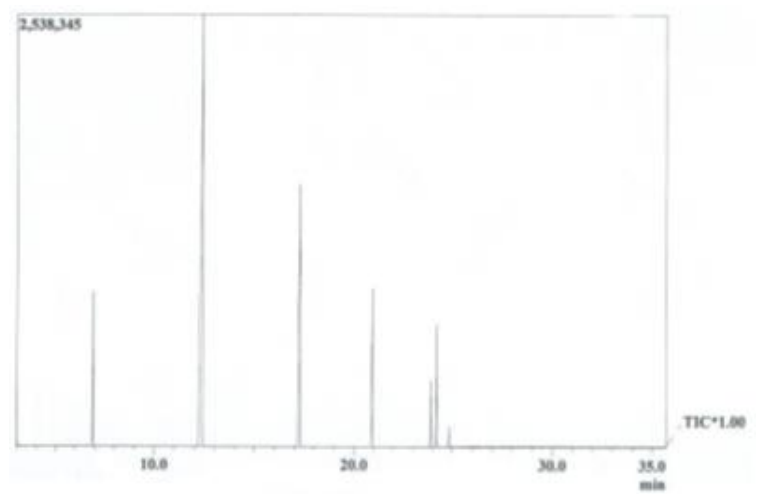

Fig 2:- GCMS Image of Coconut oil Biodiesel

The chromatographic outline of these fatty acid presented in the coconut oil is rich in saturated fatty acids, with high proportions of lauric and myristic acids. Most of the papers related to fatty acid composition study of coconut oil concentrates and depicted on the above mentioned (lauric and mystic) types of compounds. In this case of study also impulses on the presence of such compounds and have sufficient amount of products were available.

\begin{tabular}{|c|c|c|}
\hline \multicolumn{3}{|c|}{ Fatty Acids Composition of coconut oil Bioidesel } \\
\hline Fatty Acids & & Coconut Oil (\%) \\
\hline \multicolumn{3}{|c|}{ Saturated } \\
\hline Caprylic & $\mathrm{C} 8$ & 7 \\
\hline Capric & $\mathrm{C} 10$ & 7 \\
\hline Lauric & $\mathrm{C} 12$ & 48 \\
\hline Myristic & $\mathrm{C} 14$ & 14 \\
\hline Palmitic & $\mathrm{C} 16$ & 9.5 \\
\hline Stearic & $\mathrm{C} 16$ & 2.6 \\
\hline Arachidic & $\mathrm{C} 20$ & 1.4 \\
\hline \multicolumn{3}{|c|}{ Unsaturated fatty acids } \\
\hline \multicolumn{3}{|c|}{ Monosaturated } \\
\hline Oleic & $\mathrm{C} 18$ & 6.5 \\
\hline \multicolumn{3}{|c|}{ Polysaturated } \\
\hline Linoleic acid & $\mathrm{C} 18$ & 1.8 \\
\hline Linolenic acid & $\mathrm{C} 18$ & 1 \\
\hline
\end{tabular}

Table 1:- Fatty Acid composition of Coconut oil Biodiesel
From the observation on the fatty acid composition study reveals that coconut oil has $88 \%$ saturated fatty acid and only $8.5 \%$ unsaturated fatty acid, mostly composed of oleic acid $(5.5 \%)$. These results are comparable with the data of some of the researchers were worked in this field of technology. The presence of lauric acid (44.6\%) was found in coconut oil. This result is in track with the researchers $[18,19]$, they reported that coconut oil is major source of lauric acid, with significant food and non-food uses.

\section{> Thermo-Gravimetric Analysis (TGA)}

The Thermo-Gravimetric Analysis (TGA) of the biodiesel prepared by the transezterification process of coconut oil using Potassium hydroxide as catalyst. In this work, the thermal stability of coconut oil biodiesel is analysed and test with coconut oil was done. The sample which is allowed to test under conditioned temperature. The sample undergoes physical or chemical changes, as the temperature varies. This method is used to determine a material's thermal stability and its fraction of volatile components [20]. Initial horizontal portion indicates the region where there is no mass change, which indicates the material is thermally stable.

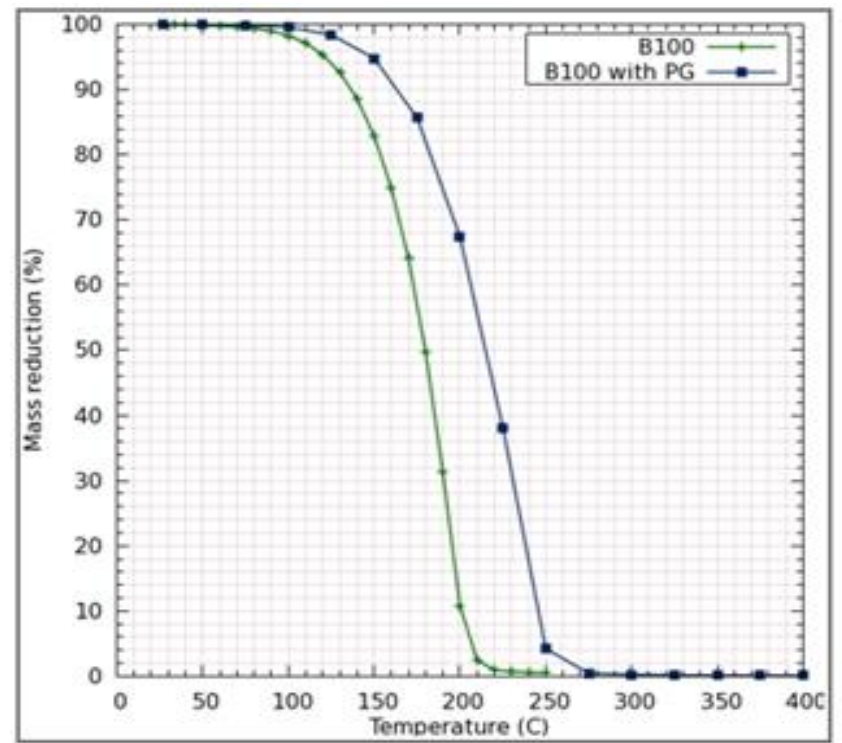

Fig 3:- TGA Image of Coconut oil Biodiesel

The slanting down portion indicates the mass loss. And it can be due to dehydration, decomposition or evaporation. In $\mathrm{B} 100$ there is no appreciate mass loss up to $80^{\circ} \mathrm{C}$ from $33.85^{\circ} \mathrm{C}$, which shows the horizontal portion. Up to $80^{\circ} \mathrm{C} \mathrm{B100}$ is thermally stable. After which the slope begins, which indicates the mass loss, which is due to dehydration, decomposition or evaporation. From the percentage mass loss, the number of molecules of hydrated water lost within the temperature range can be determined.

\section{B. Physiochemical Properties of Biodiesel}

Biodiesel produced from coconut oil has comparable fuel properties with the conventional fossil diesel. Based on the ASTM standards, the testing were done under prescribed conditions. A comparative study of fuel properties with the commercial diesel fuel, neat biodiesel 
fuel as per the standard values prefer in the standard books, with the blends of blends virgin coconut oil have been carried out in this work to find out suitable blending of biodiesel

\begin{tabular}{|l|c|c|c|c|}
\hline \multicolumn{5}{|c|}{ Physiochemical Properties ofC Coconut Oil Biodiesel } \\
\hline Fuel Property & Unit & Diesel & Biodiesel & Sample \\
\hline Fuel Standard & & ASTM D 75 & ASTM PS 121 & \\
\hline Fuel Composition & & C10-C21 HC & C12-C22 FAME & \\
\hline Viscosity & $\mathrm{mm} 2 / \mathrm{sec}$ & $1.3-4.1$ & $1.9-6.0$ & 2.4 \\
\hline Density & $\mathrm{Kg} / \mathrm{m} 3$ & 707.9 & 732.8 & 795.3 \\
\hline Flash point & ${ }^{*} \mathrm{C}$ & $60-80$ & $100-170$ & 62 \\
\hline Fire Point & ${ }^{*} \mathrm{C}$ & $70-90$ & $110-180$ & 68 \\
\hline Calorific Value & $\mathrm{MJ} / \mathrm{kg}$ & 45.5 & $37.27-41.2$ & 38 \\
\hline
\end{tabular}

Table 2:- Physiochemical properties of Biodiesel fuel with Diesel fuel.

Available physiochemical data of Virgin coconut oil biodiesel, clearly depicts the differences of biodiesel fuel with Commercial diesel engine. The shape of the fuel spray is strongly influenced by the viscosity of the fuel. If the viscosity is high, it causes high penetration of spray and low atomization. Table. 2 indicates that at room temperature, biodiesel fuel derived from virgin coconut oil have almost the similar viscosity and it is about $1.5-2 \%$ higher than fossil fuel. A comparable viscosity as that of diesel fuel is achieved by slight preheating. Therefore diesel blends does not cause change in fuel spray pattern. And without modifications fuels can be used in diesel engines.

With higher blending of biodiesel, the flash point of the bio fuel is higher. It is because when compare to than diesel fuel, the biodiesel has lower energy density, so for producing same amount of energy as compared to diesel fuel higher amount of compression ratio is required. Finally, from the physiochemical properties we can conclude that without any engine modifications the prepared biodiesel fuel can be blended with conventional diesel fuels.

\section{Engine Performance}

The performance tests were conducted on a diesel engine with diesel and Biodiesel diesel fuel blends. The final product of biodiesel from coconut oil was used as an alternative fuel to operate a diesel engine and the performance data were recorded. Brake thermal Efficiency, Specific fuel consumption of the engine was measured for Diesel, B10-D90, B20-D80, and B30-D70 blends. The variation in BSFC and BTE for Biodiesel blends at different engine load conditions.

The Figure.4 shows that, as a function of load, the brake thermal efficiency of diesel engine obtained for different biodiesel blends of virgin coconut oil and diesel. The graph is plotted such that with on the $\mathrm{x}$ axis Brake power and on the $\mathrm{y}$-axis Brake thermal efficiency are plotted. For Biodiesel with $20 \%$ of blend (B-20), shows maximum BTE. Due to low volatility and higher density of the methyl ester of waste coconut oil we get low efficiency, which affects mixture formation and leads to slow combustion.

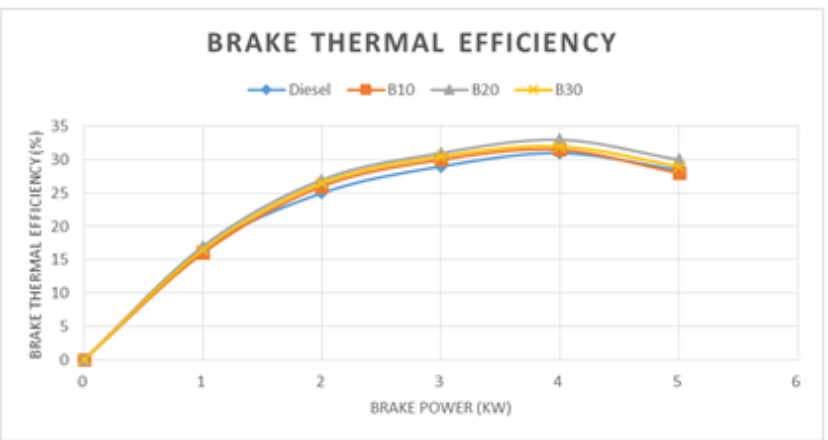

Fig 4:-Graphical representation of Brake thermal Efficiency. (Coconut Oil blends vs Diesel fuel)

Results showed that while compared to baseline diesel fuel at all engine loads, the SFC for B20-D80 is higher. Fig. 5 shows that when compared with diesel fuel, the increase of SFC is due to the lower heating value of biodiesel and ethanol blends. Under all engine load operations (brake power), the BTE of biodiesel fuel and biodiesel blended diesel fuel is higher than that of diesel fuel. For B20-D80 blends, there is increase in the combustion efficiency and BTE due to increased availability of fuel bound oxygen content in the oxygenated fuels. The overall efficiency of the engine is measure by SFC. It is inversely related with the efficiency of brake thermal. So, higher the overall efficiency of the engine, lower is the value of SFC. When the engines are fueled with different types of fuel blends, Brake thermal efficiency is employed. The figure shows that the BTE is always lower than that of diesel fuel and SFC for biodiesel is always higher.

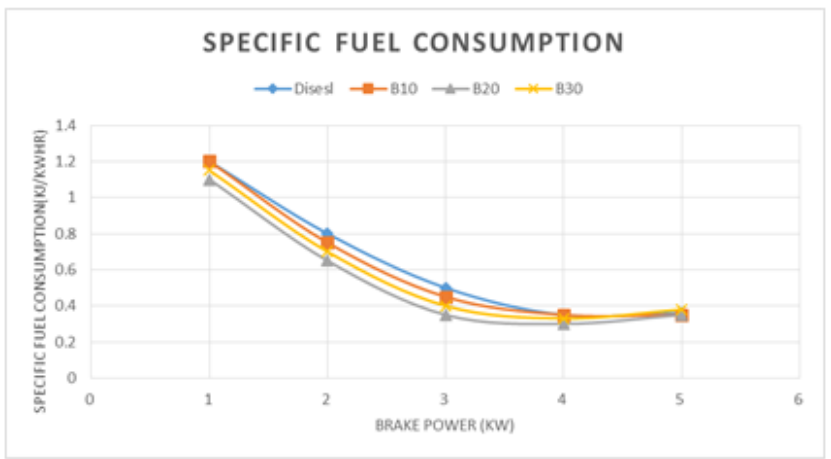

Fig 5:- Graphical representation of Specific Fuel Consumption. (Coconut Oil blends vs Diesel fuel)

\section{Emission Characteristics}

The load tests were conducted by varying the dosing level of biodiesel fuel in the diesel and the emissions such as carbon monoxide, carbon dioxide, hydrocarbon and oxides of nitrogen emissions were measured using a standard emission analyzer, coupled with the Diesel engine. Several norms were published by the Indian governments to reduce the emission from automobile and industries, Due to this act, as an initiative, Delhi government banned diesel 
engine cars from the city to reduce the emission for better clean environment. But most of the citizens have at Delhi has Diesel engine cars, due to mileage. But this scenario adversely effected them. So if they were adopting these types of biodiesel fuels for fuel additives into the fuel means, we can reduce the emission characteristic to a great extent, also protect the environment.

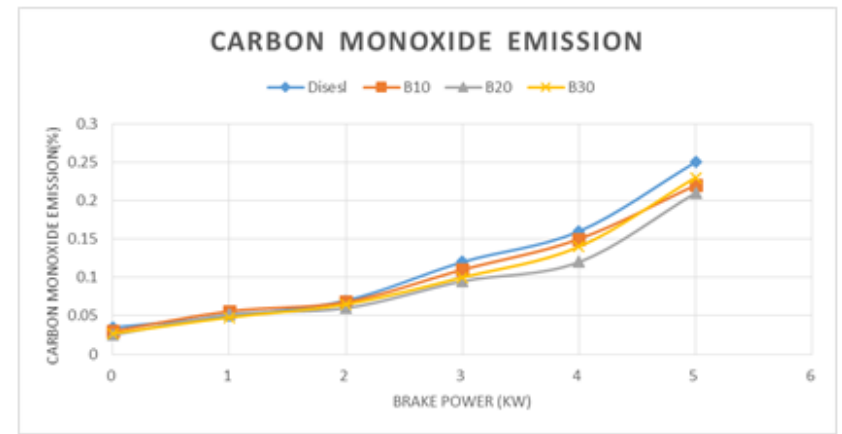

Fig 6:- Graphical representation of Carbon Monoxide Emission. (Coconut Oil blends vs Diesel fuel)

With the diesel fuel, the variation of $\mathrm{CO}$ emissions with varying engine load for different biodiesel blends is compared and shown in Figure 6. With the increase in biodiesel percentage in blends, the carbon monoxide emission gets decreases. For B20-D80 diesel blend, carbon monoxide emission is obtained is lower for all loads. For B10-D90 highest carbon monoxide emission is obtained but lower than diesel fuel. For blend B20, the CO emission are minimum which is having a value of $0.12 \%$ for $75 \%$ load. In the case of biodiesel blended diesel fuels, the amount of $\mathrm{CO}$ was lower when compared to commercial diesel fuel, because that biodiesel fuel consists of oxygen molecules and leads to complete combustion and reduction of $\mathrm{CO}$ emission. Some of the important factors which influences the reduction of emissions, which mainly linked with the engine design and the operating factors. Moreover, the proper air-fuel mixture in the engine also improves the engine performance and reduces the emission characteristics $t$ a great extent.

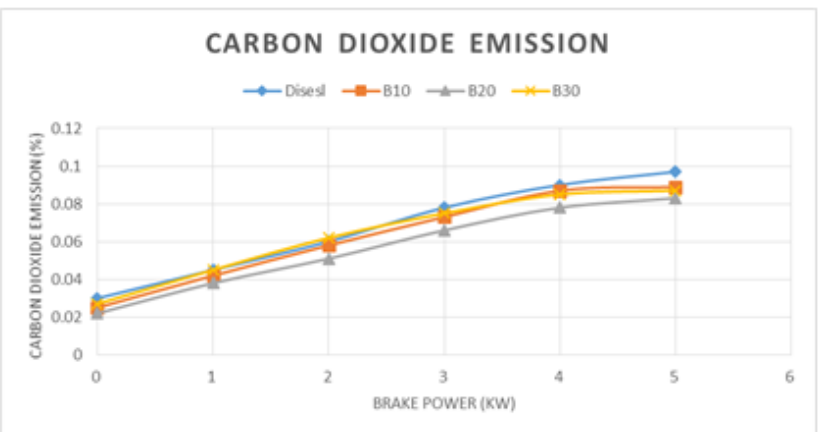

Fig 7:- Graphical representation of Carbon Dioxide Emission. (Coconut Oil blends vs Diesel fuel)

Carbon dioxide is considered as the major reason behind the depletion of greenhouse. The gases emit from the automobiles, which consist of smaller amounts of methane and nitrous oxide. These gases are released during the combustion of fuels, Carbon monoxide ( $\mathrm{CO}$ ) will be formed, due to shortage of air (process in air-fuel mixture) or because of low gas temperature, which leads to incomplete of fuel. Due to the presence of oxygen contents in the virgin coconut oil reduces the $\mathrm{CO}$ emissions also results in complete combustion of the fuel. Some other researchers were perceives in their experimental analysis that, due to the lower possibility of formation of rich fuel, is because of higher cetane number of biodiesel blends.

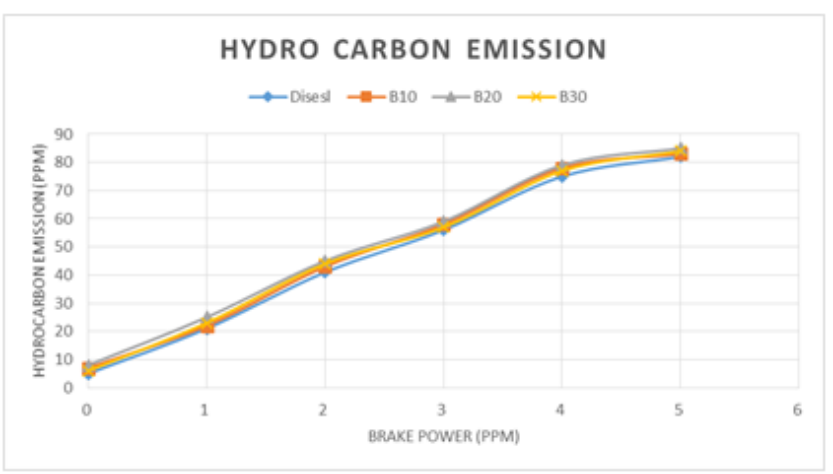

Fig 8:- Graphical representation of Hydro Carbon Emission. (Coconut Oil blends vs Diesel fuel)

Figure. 8 shows the variation of hydrocarbon emission with load for different biodiesel blends. With the increase in load, the $\mathrm{HC}$ emissions increases. With increasing biodiesel percentage in the blend, $\mathrm{HC}$ emissions decreases, due to the oxygen content in biodiesel. Thus, HC level decreases due to that reductions indicate that more complete is combustion of the fuels.

For B30-D70, the $\mathrm{HC}$ emission are minimum having value of $4 \mathrm{ppm}$ for $0 \%$ load and for B10-D90 full load it is having maximum value of 86 PPM.

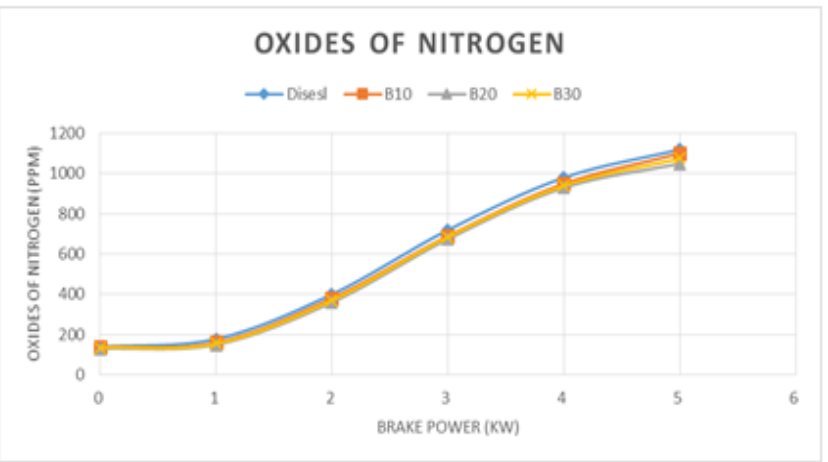

Fig 9:- Graphical representation of Oxides of Nitrogen. (Coconut Oil blends vs Diesel fuel)

Figure. 9 presents NOx emissions for diesel fuel and biodiesel blends in the graphical figure. The NOx emissions for blends are found higher than diesel fuel. From the experimental analysis, we found that brae thermal efficiency of the biodiesel fuel is directly proportional to the oxides of nitrogen emissions. It has been reported in several reports that, the formation of NOx emissions are strongly dependent upon the equivalence ratio, oxygen concentration and burned gas temperature. When compared to diesel fuel, the increase in NOx at $100 \%$ was $1200 \mathrm{ppm}$. At all load conditions (from zero to top), the NOx emission 
for coconut biodiesel blends is higher when compared to diesel fuel due to the oxygen content of biodiesel fuel.

\section{CONCLUSION}

The present research work is to investigate the engine performance and emissions characteristics of a diesel engine operating on virgin coconut oil biodiesel blends and to compare these results with those operating on diesel fuel. The biodiesel blends such as B10-D90, B20-D80 and B30D70 respectively.

Compared to diesel fuel, Brake Thermal Efficiency for biodiesel blends were increased, and the specific fuel consumption values for biodiesel blends were varies when compared to diesel fuel due to lower (as suitable for diesel engines) densities. In case of engine exhaust gas emissions, $\mathrm{CO}_{2}, \mathrm{HC}$ and $\mathrm{CO}$ emissions were reduced whereas, and NOx emissions were increased for B20 when compared to diesel fuel.

With the help of engine test result we can say that without any engine modifications biodiesel from coconut oil can be used as alternate fuel over convention diesel engine. After transezterification, the viscosity of waste coconut oil gets reduced. We can see that to those of diesel the viscosity and specific gravity of the waste coconut oil methyl ester formed transezterification were found close. When compared to diesel, the flash point of all the blends was higher. Over diesel, biodiesel also showed higher flash point and found safe for storage. The test results showed that the properties of biodiesel showed similar properties of diesel, so it can replace diesel fuel and is applicable in compression ignition engines. When an engine is made run with biodiesel and its blend the $\mathrm{HC}$ and $\mathrm{CO}$ emission gets reduced due to complete combustion of fuel when compared to diesel fuel.

From the experimental results it is suggest that used cooking oil biodiesel could be a good substitute fuel for diesel engine in the near future. It can be concluded that $20 \%$ blend of biodiesel with diesel (B20-D80) could be used as conventional diesel engine in view of engine performance and reduction in engine emissions.

\section{REFERENCES}

[1]. Hegab, A., La Rocca, A., \& Shayler, P. (2017). Towards keeping diesel fuel supply and demand in balance: Dual-fuelling of diesel engines with natural gas. Renewable and Sustainable Energy Reviews, 70, 666-697.

[2]. Graboski, M. S., \& McCormick, R. L. (1998). Combustion of fat and vegetable oil derived fuels in diesel engines. Progress in energy and combustion science, 24(2), 125-164.

[3]. Kutkoski, R. F., Rodrigues, F. J., Laverde Jr, A., Souza, N. E., Santos, I. A., \& Cótica, L. F. Synthesis of Aluminum Based Heterogeneous Catalysts for the Biodiesel Production.
[4]. Zacharia, R. (2015). Review of solid state hydrogen storage methods adopting different kinds of novel materials. Journal of Nanomaterials, 2015.

[5]. Maitera, O. N., Louis, H., Dass, P. M., Akakuru, U. O., \& Joshua, Y. (2017). Production and characterization of biodiesel from coconut extract (Cocos nucifera). World News of Natural Sciences, 9, 62-70.

[6]. Thangarasu, V., \& Anand, R. (2019). Comparative evaluation of corrosion behavior of Aegle Marmelos Correa diesel, biodiesel, and their blends on aluminum and mild steel metals. In Advanced Biofuels (pp. 443-471). Woodhead Publishing.

[7]. Abdulkareem, A. S., Odigure, J. O., \& Kuranga, M. B. (2010). Production and characterization of biofuel from coconut oil. Energy Sources, Part A: Recovery, Utilization, and Environmental Effects, 32(5), 419-425.

[8]. Lang, X., Dalai, A. K., Bakhshi, N. N., Reaney, M. J., \& Hertz, P. B. (2001). Preparation and characterization of bio-diesels from various bio-oils. Bioresource technology, 80(1), 53-62.

[9]. Ramadhas, A. S., Jayaraj, S., \& Muraleedharan, C. (2008). Experimental investigations on diethyl ether as fuel additive in biodiesel engine. International Journal of Global energy issues, 29(3), 329-336.

[10]. Atadashi, I. M., Aroua, M. K., Aziz, A. A., \& Sulaiman, N. M. N. (2013). The effects of catalysts in biodiesel production: A review. Journal of industrial and engineering chemistry, 19(1), 14-26.

[11]. Arunkumar, M., Kannan, M., \& Murali, G. (2019). Experimental studies on engine performance and emission characteristics using castor biodiesel as fuel in CI engine. Renewable Energy, 131, 737-744.

[12]. O. N. Maiteral, H. Louis2, P. M. Dass1, U. O. Akakuru, Y. Joshua. Production and characterization of biodiesel from coconut extract (Cocos nucifera) An International Research On-line Journal.

[13]. Kalam, M. A., Husnawan, M., \& Masjuki, H. H. (2003). Exhaust emission and combustion evaluation of coconut oil-powered indirect injection diesel engine. Renewable Energy, 28(15), 2405-2415.

[14]. Bawalan, D. D., \& Chapman, K. R. (2006). Virgin Coconut Oil. Production Manual for Micro and Village Scale Processing. FAO Regional Office for Asia and the Pacific, Bangkok. Food and Agriculture Organization of the United Nations. First Published February D, 2006.

[15]. Jayadas, N. H., Prabhakaran Nair, K., \& Ajithkumar, G. (2005, January). Vegetable Oils as Base Oil for Industrial Lubricants: Evaluation Oxidative and Low Temperature Properties Using TGA, DTA and DSC. In World Tribology Congress (Vol. 42010, pp. 539540).

[16]. Alex, Y., Earnest, J., Varghese, A., \& Achankunju, A. Synthesis and Testing on Engine Characteristics of Bio-diesel Obtained by Orange-Peel Oil Methyl Ester Blended with Conventional Diesel Fuel.

[17]. Alex, Y. (2008). Quantitative Analysis of fatty acids on Biodiesel fuel derived from Virgin Coconut Oil. 
[18]. Gregorio, C.C., Fatty acids and derivatives from coconut oil. Bailey's Industrial Oil and Fat Products, Sixth edition, John Wiley \& Sons, Inc., 2005

[19]. Gopala Krishna A.G., Gaurav Raj, Ajit Singh Bhatnagar, Prasanth Kumar P.K. and Preeti Chandrashekar, Coconut Oil: Chemistry, Production and Its Applications - A Review, Indian Coconut Journal, 2010, 15-27

[20]. Dayrit, M.F., Buenafe, M.O.E., Chainani T.E., de Vera, S.I.M., Dimzon, D.I.K., Gonzales, G.E., Santos, R.J.E., Standards for essential composition and quality factors of commercial virgin coconut oil and its differentiation from RBD coconut oil and copra oil, Philippine Journal of Science 2007, 136(2), 119-129 